\title{
Educação infantil em tempos de pandemia: as mini-histórias como ferramentas de apoio às famílias
}

\author{
Early childhood education in pandemic times: mini-stories as tools of \\ support to families
}

\section{Educación de la primera infancia en tiempos de pandemia: mini historias como herramientas para apoyar a las famílias}

https://orcid.org/0000-0002-1244-6232

Ana Paula Rampelotto ${ }^{2}$

https://orcid.org/0000-0002-880I-6626

Angelita Maria Machado 3

https://orcid.org/0000-000 I-7796-0200

Resumo: Esse artigo traz um relato de experiência de três professoras de bebês e crianças bem pequenas da Unidade de Educação Infantil Ipê Amarelo (UEIIA), da Universidade Federal de Santa Maria (UFSM), em um momento de distanciamento social devido à pandemia do coronavírus, em que nos questionamos sobre como garantir os direitos das crianças e ser apoio às famílias. Diante disso, e sabendo dos interesses comuns dos bebês e das crianças bem pequenas de nossa turma, temos apostado na criação de mini-histórias (FOCHI, 2019). As famílias têm relatado contentamento ao receber as mini-histórias e apreciá-las junto com os bebês e as crianças bem pequenas. Assim, essas escritas têm se mostrado ferramentas potencializadoras de momentos prazerosos de fortalecimento de vínculos entre os familiares e as crianças (REYES, 20I0; PARREIRAS, 20I2), bem como são formas de manter memórias afetivas dos colegas, das professoras, da UEIIA e dos momentos lá vividos, assim como tem nos ajudado a acalmar nossos corações diante das incertezas que hoje vivemos.

Palavras-chave: Educação Infantil. Pandemia. Apoio às famílias.

\footnotetext{
' Doutora em Educação pela UFSM. Docente na Unidade de Educação Infantil Ipê Amarelo, da Universidade Federal de Santa Maria. E-mail: profclaucia@gmail.com.

${ }^{2}$ Especialista em Educação Ambiental pela UFSM - Universidade Federal de Santa Maria. Docente na Unidade de Educação Infantil Ipê Amarelo, da Universidade Federal de Santa Maria. E-mail: paulinhadecian@gmail.com.

${ }^{3}$ Licenciada em Pedagogia pela UFSM. Docente na Unidade de Educação Infantil Ipê Amarelo, da Universidade Federal de Santa Maria. E-mail: angelitamachado026@gmail.com.
} 
Abstract: This article reports the experience of three teachers of babies and very young children at the Unidade de Educação Infantil Ipê Amarelo (UEIIA), at the Federal University of Santa Maria (UFSM), at a time of social distancing due to the coronavirus pandemic, in which we question ourselves about how to guarantee children's rights and how to be supportive of families. In view of this, and knowing the common interests of the babies and the very young children in our class, we have been confident in the creation of mini-stories (FOCHI, 2019). Families have reported contentment in receiving the mini-stories and enjoying them together with babies and very young children. Thus, these writings have shown to be tools that potentialize pleasurable moments of bond strengthening between family members and children (REYES, 20I0; PARREIRAS, 20I2), as well as being a way of maintaining affectionate memories of classmates, teachers, the UEIIA, and the moments lived there, in addition to helping calm our hearts in the face of the uncertainties that we live today.

Keywords: Early Childhood Education. Pandemic. Support to families.

Resumen: Este artículo trae un relato de experiencia realizado por tres maestros de bebés y niños muy pequeños de la Unidad de Educación Infantil Ipê Amarelo (UEIIA), de la Universidad Federal de Santa María (UFSM), en un momento de distanciamiento social debido a la pandemia de coronavirus. Nuestras preocupaciones sobre nuestra práctica docente son constantes, principalmente con respecto a cómo garantizar los derechos de los niños, cómo garantizar su escucha y cómo apoyar a las familias en ese momento. Por ello, y conociendo los intereses comunes de los bebés y niños muy pequeños en nuestra clase, hemos apostando en la creación de mini historias a partir de los registros y observaciones producidos antes de este período de distanciamiento social en el que vivimos. Las familias han informado que están felices de recibir las mini historias y disfrutarlas con bebés y niños muy pequeños. Por lo tanto, estos escritos han demostrado ser herramientas potenciadoras de momentos agradables para el fortalecimiento de los lazos entre los miembros de la familia y los niños, a la vez son formas de mantener recuerdos afectivos de colegas, maestros, UEIIA y los momentos vividos allí, igualmente ayudan a calmar nuestros corazones ante las incertidumbres que experimentamos hoy.

Palabras-clave: Educación en la primera infancia. Pandemia. Apoyo a las familias.

\section{Introdução}

Este texto apresenta nosso relato de experiência enquanto professoras de bebês e crianças bem pequenas4 em tempos de distanciamento social. Atuamos na Unidade de Educação Infantil Ipê Amarelo (UEIIA), uma Unidade Universitária de Educação Infantil (BRASIL, 20II), que se situa na Universidade Federal de Santa Maria (UFSM), no interior do estado do Rio Grande do Sul (RS). A UEIIA encontra-se com suas atividades presenciais suspensas desde a segunda quinzena do mês de março, devido à pandemia do coronavírus 5 .

Essa pandemia exige um distanciamento social. A necessidade de nos isolarmos como prevenção à Covid-196 veio de modo repentino, sem muitas possibilidades de preparação para a situação. Com isso, subitamente, apresentou-se o home office e a necessidade de pensar a Educação

\footnotetext{
${ }^{4}$ Com base em Barbosa (2009), neste documento estamos considerando bebês as crianças de 0 a 18 meses e crianças bem pequenas as crianças que têm entre 19 meses e 3 anos e 11 meses.

5 "Você sabe o que são coronavírus? São uma grande família de vírus, conhecidos desde meados de 1960, que causam infecções respiratórias em humanos e animais. $O$ novo coronavírus ainda não havia sido identificado em humanos e agora está sendo amplamente estudado por todo o mundo”. (Departamento de Saúde Coletiva UFSM, 2020. Disponível em: https://www.ufsm.br/wp-content/uploads/2020/03/coronavirus.pdf

6 "O que é COVID-2019? É uma doença causada pelo novo tipo de coronavírus identificado neste ano, que leva o nome de SARS-CoV-2. Ele pertence à família de vírus de mesmo nome que causa infecções respiratórias." Fonte: Secretaria da Saúde do RS - RS, 2020. Disponível em: https://coronavirus.rs.gov.br/o-que-e.
} 
Infantil, a manutenção dos vínculos das crianças com os adultos e delas entre si, bem como a escuta sensível nesse momento de distanciamento. Como mobilizar isso? Como garantir os direitos das crianças? Como ser apoio às famílias nesse momento?

Diante desses questionamentos viemos estudando, refletindo e, enquanto professoras em turma de bebês e crianças bem pequenas na UEIIA, considerando as especificidades desses sujeitos de direitos (BRASIL, 2010) e suas famílias. Com isso, construir nosso fazer pedagógico nesse momento e atenuar os anseios acima citados.

Ressaltamos que esse processo reflexivo não é simples, pois envolve uma gama de emoções que sentimos diante das incertezas desse momento, diante dos anseios pessoais e profissionais que ele provoca. Ainda, o home office não nos permite observar, registrar, refletir, planejar e organizar propostas a partir do nosso olhar cotidiano.

Sendo assim, esse momento de distanciamento social tem nos exigido repensar o papel docente, fazendo com que nos reinventemos e busquemos ser apoio essencial para as famílias, com foco nas relações e vínculos familiares. Além disso, também temos pensado e buscado promover a manutenção de nossos vínculos com as crianças e delas entre si.

Diante disso e tendo identificado grande interesse dos pequenos7 de nossa turma por livros e histórias, pensamos na construção de mini-histórias para compartilhar com as famílias. Buscando, assim, algo que pudesse ser prazeroso e mobilizasse momentos afetuosos, cheios de boas memórias dos dias na UEIIA, tanto às famílias, quanto para nós, professoras, especialmente nesse período em que vivemos.

Entendemos que as mini-histórias são uma estratégia pedagógica para compor e compartilhar momentos significativos vividos pelas crianças (FOCHI, 2019), os quais contribuem para rememorar e evidenciar sentidos e significados, bem como promover o diálogo sobre algo comum ou peculiar do contexto educativo.

Assim, apresentamos aqui um pouco desse processo que nos levou a construir as minihistórias, como viemos fazendo isso e o que viemos percebendo que delas advém.

\section{A pandemia e o distanciamento social: o que nos fez (re)inventar?}

Chegou a pandemia do coronavírus, que trouxe o necessário distanciamento social. E agora? Professoras de infância, de bebês e crianças bem pequenas, o que fazer diante dessa situação? No início ficamos em inércia, sem assimilar direito. Precisávamos saber sobre o vírus, sobre a importância do distanciamento, buscar os fundamentos que norteiam a Educação Infantil e os

\footnotetext{
${ }^{7}$ Carinhosamente entre as professoras, chamamos os bebês e as crianças bem pequenas de nossa turma de "nossos pequenos", termo também usado neste texto.
} 
Educação infantil em tempos de pandemia: as mini-histórias como ferramentas de apoio às famílias princípios do nosso trabalho pedagógico na UEIIA para, assim, podermos refletir e pensar no que fazer.

Então fomos a isso e na busca de informações sobre o vírus veio o receio, pois é um agente novo, com altíssimo grau de transmissão8. Diante disso, surgiram as preocupações, tanto pessoais quanto profissionais. Preocupações com a preservação da vida e com a garantia dos direitos das crianças.

$\mathrm{Na}$ UEIIA, então, organizou-se um ambiente virtual de formação, no qual, inicialmente, retomamos o estudo das Diretrizes Curriculares Nacionais para a Educação Infantil (BRASIL, 20I0), da Base Nacional Comum Curricular - BNCC (BRASIL, 2018), do Projeto Político Pedagógico (2019) da Unidade e também assistimos a um vídeo do professor Paulo Fochi9, um dos assessores na elaboração da $\mathrm{I}^{\mathrm{a}}$ e $2^{\mathrm{a}}$ versão da BNCC. Nesse vídeo ele responde perguntas de uma secretaria municipal de educação do RS sobre a BNCC para a Educação Infantil.

Subsidiadas por esse material buscamos pensar em nossos pequenos e suas famílias. Como poderíamos manter nosso vínculo com eles? Como poderíamos ser suporte para as famílias vivenciarem momentos prazerosos e afetuosos junto com as crianças, nesse período em que elas estão em casa devido à pandemia do coronavírus?

Revisitando nossos registros identificamos que os espaços para leitura e apreciação de livros e histórias encantavam os bebês e as crianças bem pequenas. Então, pensamos na construção de mini-histórias, vendo nelas uma possibilidade de propor às famílias um momento de ser e estar junto com as crianças, assim, potencializando o estabelecimento de conexões entre crianças e adultos. Nesse sentido, Parreiras (2012) já dizia que os livros, além de serem pontes de comunicação das crianças pequenas com o mundo, trazem a possibilidade da constituição de afetos.

Ainda, Paulo Fochi (2019) também nos apresenta as mini-histórias como: “[...] rapsódias da vida cotidiana que, ao serem narradas textual e imageticamente, tornam-se especiais pelo olhar do adulto que as acolhe, interpreta-as, e dá valor para a construção da memória pedagógica" (FOCHI, 2019, p.49). O autor também define que essas escritas são compostas por algumas fotografias e um pequeno texto (FOCHI,20I9).

Buscamos, então, compartilhar as memórias pedagógicas com as famílias ao apresentar as mini-histórias, com o intuito de promover o acolhimento dos adultos, que são as pessoas próximas aos bebês e crianças bem pequenas nesse momento. Com isso, intentamos que esses adultos

\footnotetext{
8 Fonte e mais informações disponíveis em: https://www.scielo.br/scielo.php?pid=SOI003984202000020000 I \&script=sci_arttext\&tlng=pt.
}

\footnotetext{
${ }^{9}$ Disponível em: https://www.youtube.com/watch?v=HLk7hsj3LUk.
} 
pudessem conhecer e se sensibilizar com as mini-histórias, compartilhá-las com seus pequenos e tocar, sentir, acolher, abraçar eles, criando momentos afetuosos de conexão.

Assim, tentamos garantir a nossos pequenos, através da sensibilização das famílias, os direitos de aprendizagem e desenvolvimento previstos na BNCC - "conviver, brincar, participar, explorar, expressar, conhecer-se" (BRASIL, 20I8).

A partir de nossas mini-histórias buscamos trazer de maneira poética, para crianças e adultos, a possibilidade de relembrar dos colegas, das professoras, dos espaços da UEIIA, dos momentos lá vividos e, com elas, também auxiliar na compreensão do que estamos vivenciando.

Abaixo, na figura I, apresentamos algumas de nossas mini-histórias:

Figura I: Imagens de algumas das mini-histórias por nós escritas e compartilhadas com as famílias 10

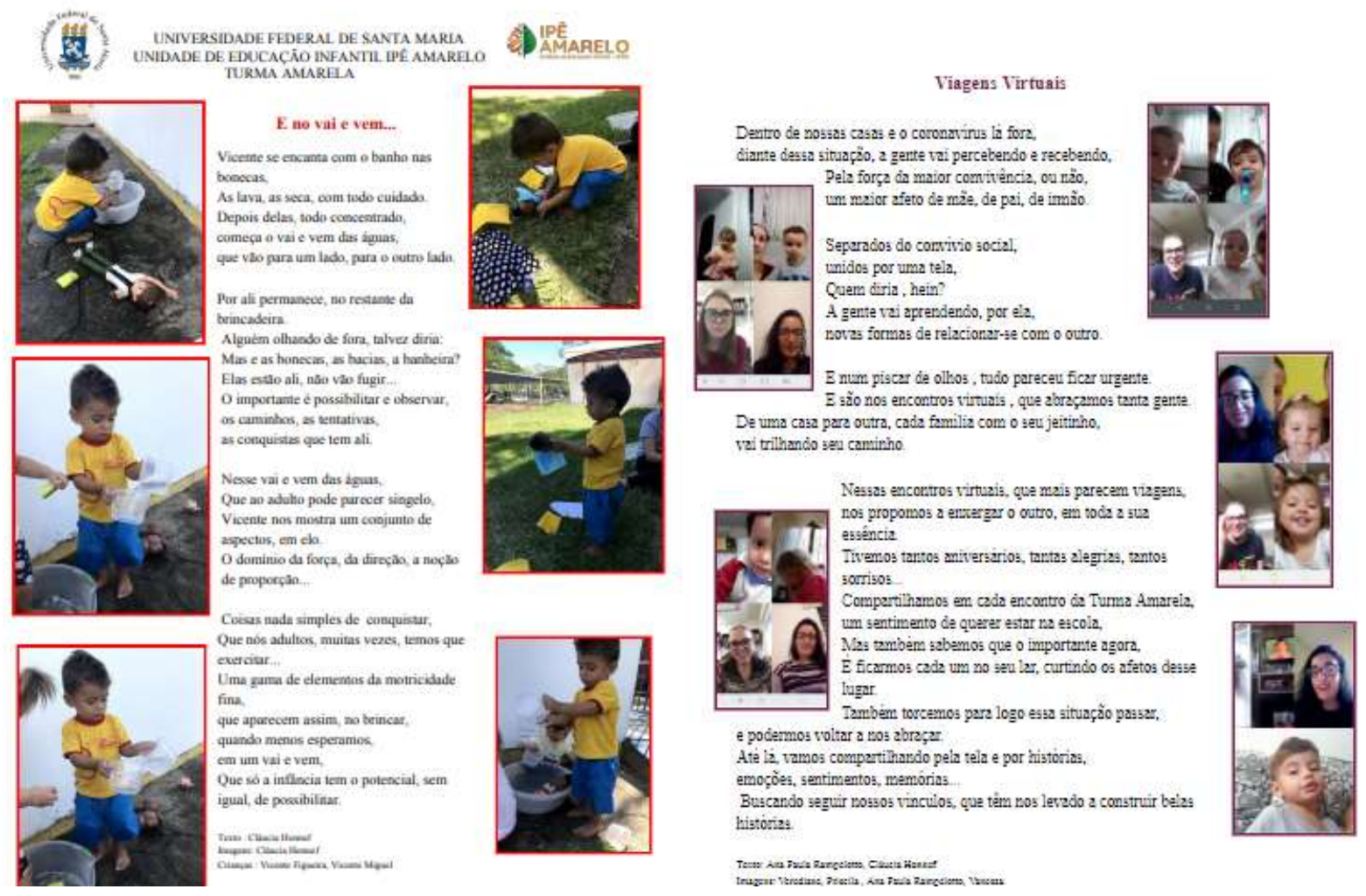

Fonte: Acervo pessoal das autoras, 2020.

A organização das mini-histórias está acontecendo a partir de nossos registros fotográficos e escritos sobre as crianças, organizados com base nas observações que cada professora realizou e

\footnotetext{
${ }^{10}$ Informamos que foram obtidas com as famílias autorização para uso de imagem e do nome das crianças que aparecem nas mini-histórias, bem como se obteve autorização para uso dos relatos dos adultos das famílias, a nós enviados por aplicativo de mensagem.
}

Olhar de professor, Ponta Grossa, v. 24, p. I-10, e-16064.034, 2021.

Disponível em <https://revistas2.uepg.br/index.php/olhardeprofessor> 
Educação infantil em tempos de pandemia: as mini-histórias como ferramentas de apoio às famílias realiza, individualmente, antes e durante a suspensão das atividades presenciais da Unidade. É nesse movimento de partilharmos ideias e impressões com as colegas docentes da turma que as minihistórias se materializam e são construídas e, dessa forma, buscamos um trabalho de colaboração entre pares 3 , o que objetiva nos fortalecer enquanto professoras de crianças bem pequenas.

A construção das mini-histórias a partir de nossos registros tem sido um desafio que nos impulsiona a refletir sobre nosso saber e nosso fazer, a olhar a individualidade de cada criança e as construções coletivas da turma. Algumas mini-histórias possuem palavras rimadas, quase minipoemas, histórias que descrevem um momento específico de uma criança ou de um grupo de crianças. Outras mini-histórias retomam as experiências, vivências e conhecimentos oportunizados a nossos pequenos na sala da turma, ou os quais eles descobriam nos espaços externos da Unidade.

Percebemos que esse movimento de criar e compartilhar as mini-histórias com as famílias tem propiciado importantes experiências para nós, professoras, e para nossos pequenos, assim como para as famílias.

Através da construção das mini-histórias compartilhamos momentos que aconteceram entre as crianças e entre professoras e crianças. Entendemos que essa organização e sistematização auxilia a amenizar a saudade dos momentos em que passamos juntos, assim como possibilita recordarmos brincadeiras, interações, emoções, olhares, deixando viva a lembrança da UEIIA e de tudo o que vivenciamos de significativo durante o tempo em que estivemos juntos fisicamente.

Além disso, o processo de organizar e sistematizar nossas observações em mini-histórias nos desafia a ter um olhar sensível e investigativo às experiências de nossos pequenos, buscando apresentá-lo nas mini-histórias de modo a também tentar sensibilizar e convidar as famílias a observarem seus pequenos, oportunizarem e serem apoio às descobertas e conquistas deles em suas casas.

Nesse sentido, incentivando as famílias na percepção de que, muitas vezes, o que os adultos entendem ou acreditam ser comum, como, por exemplo, o ato de passar água de um recipiente para outro, para a criança pode ser complexo e é importante que se observe e respeite as particularidades de cada uma, sempre considerando que é direito dela "conviver, brincar, participar, explorar, expressar, conhecer-se" (BRASIL, 20I8).

Vemos nisso, também, a potência das mini-histórias, ou seja, tornar visíveis às famílias esses momentos de descobertas e produções realizadas pelas crianças na UEIIA, para que possam melhor observar os pequenos e perceber elementos potencializadores de seu desenvolvimento no dia a dia, também em casa.

Os adultos das famílias, ao receberem a cada semana uma mini-história em um grupo da turma, criado no aplicativo WhatsApp, relatam o quanto gostam das escritas e sentem vir por elas o 
carinho e atenção que seus filhos, e também as famílias, recebiam presencialmente na turma. Recebemos os relatos por mensagens de texto nesse grupo do aplicativo e nos encontros virtuais que fazemos semanalmente com as famílias.

A seguir, trazemos algumas dessas mensagens, geralmente das mães, as quais serão aqui nomeadas pelas letras do alfabeto (Mãe A, Mãe B, Mãe C...). Já as crianças e professoras, quando citadas nas mensagens, serão identificadas nesse artigo pela letra inicial do nome I I.

Mãe A: “- Que lindo... obrigada profs.. este momento está sendo bem difícil pra nós, é muito bom poder sentir esse carinho."

Mãe B: “- Obrigada profe A (nome da professora) pela historinha, muito bom ter a companhia de vocês no nosso dia a dia."

Mãe C: “- Muito legal profe C (nome da professora)! A J (nome da criança) olhou e pediu "di novo mamãe"."

Mãe D: “- O VM (nome da criança) adorou também, tentava interagir e fazer o som de alguns bichos que sabia fazer."

Mãe E: “- Obrigada prof. A (nome da professora). O P (nome da criança) adorou! Está falando a palavra bola. Agora ele vira as páginas dos livros aqui em casa e fica admirando as ilustrações."

Mãe F: “- Boa noite!! Adorei e já estou ansiosa pelas próximas histórias.”

Os relatos acima nos levam a crer que estamos no caminho certo de apoio às famílias, pois se percebe neles a emoção das famílias ao ler as mini-histórias e ao aguardar pela mini-história da semana. Também, elas expressam as ações das crianças, como o maior envolvimento delas com os livros infantis em casa, as reações diante das mini-histórias que enviamos, em que as crianças pedem para olhá-las mais de uma vez e interagem, a seu modo, imitando sons de animais, nomeando as cores e as pessoas que aparecem, por exemplo.

Esses relatos remetem às possibilidades de exploração, de expressão e de reconhecimento que estão sendo apresentadas às crianças pelas famílias por meio da leitura das mini-histórias, materializando, dessa maneira, alguns direitos de aprendizagem e desenvolvimento das crianças (BRASIL, 2018). As mensagens das famílias, ao receberem as mini-histórias, também remetem ao quanto essas escritas representam um pouco da presença das professoras e da UEIIA no dia a dia das crianças, em suas casas.

\footnotetext{
" Destacamos que obtivemos autorização dos participantes do grupo referido para uso das mensagens aqui apresentadas, sendo preservada fielmente a forma de escrita das mensagens.
}

Olhar de professor, Ponta Grossa, v. 24, p. I-10, e-16064.034, 2021.

Disponível em <https://revistas2.uepg.br/index.php/olhardeprofessor> 
Educação infantil em tempos de pandemia: as mini-histórias como ferramentas de apoio às famílias

Além disso, nos momentos de encontro virtual com as famílias da turma, algumas nos contaram que, após o recebimento das mini-histórias e de orientações das professoras quanto ao ato de contar histórias, passaram a fazê-lo para as crianças antes de dormir. Também, após o movimento de compartilharmos as mini-histórias, percebemos que, em nossos encontros virtuais com as famílias, foi mais frequente ver as crianças com livros infantis, nos mostrando e mostrando os livros aos colegas.

Esses relatos nos levam a crer na manutenção de memórias afetivas dos colegas, da turma, das professoras, da UEIIA e da construção de marcas de afeto entre pais e filhos, através da leitura conjunta das histórias. Yolanda Reyes (2010) já nos dizia que nesse movimento “[...] há um profundo conteúdo emocional que circula entre as páginas" (REYES, 2010, p. 48).

Envolver-se com as histórias não é algo que nasce de repente (SANDRONI; MACHADO, 1991), mas que vai acontecendo e se constituindo, aos poucos, em uma importante oportunidade de aprendizagem e entendimento de si, do outro e da natureza.

E é nesse contexto, nessa experiência, que buscamos nos reinventar e reinventar o modo como trazemos as histórias para nosso fazer pedagógico como professoras de infância, nesse momento de pandemia. Apostamos nas mini-histórias como elementos potentes que nos auxiliam a ser apoio às famílias, acreditando que ser apoio é ser presença, mais do que dar apoio. Portanto, com as mini-histórias procuramos, também, estar presentes. Além disso, acreditamos nas minihistórias como ferramentas para momentos prazerosos de conexão entre os familiares com nossos pequenos.

\section{Considerações finais}

Diante da pandemia e do distanciamento social que ela exige, vivemos momentos bastante difíceis, de incertezas, mas que temos canalizados a fim de buscar nos reinventar. Esse movimento não é simples, é contínuo e irregular. Vivemos altos e baixos em função de nossas reflexões, emoções e anseios.

Entretanto, entendemos que ser professora da escola da infância é estar sempre disposta a pesquisar as mais diversas formas de se fazer docente, é se desafiar, é estar constantemente refletindo sobre suas propostas. Também é pensar se o que estamos propondo tem a centralidade nos bebês e crianças bem pequenas e, principalmente, se garante a eles seus direitos de brincar, conviver, participar, explorar, expressar e conhecer-se (BRASIL, 20I8).

As mini-histórias, nesse momento, fazem parte de um movimento de acolhida das crianças, das famílias, das professoras. Ainda estamos em processo de aprender a construí-las e em constante

Olhar de professor, Ponta Grossa, v. 24, p. I-10, e-16064.034, 2021.

Disponível em <https://revistas2.uepg.br/index.php/olhardeprofessor> 
reflexão sobre nosso papel, nesse período de distanciamento social, e sobre a melhor forma de apresentar as histórias para serem ferramentas de apoio às famílias diante do que elas têm vivido.

Por fim, o que podemos dizer é que esse processo de imersão nas mini-histórias, seja escrevendo, organizando, sistematizando ou lendo, tem contribuído para trazer presença, afago e compreensão nesse período em que vivemos, bem como tem se mostrado efetivo na garantia de alguns direitos de aprendizagem e desenvolvimento das crianças. Acreditamos que esse movimento que envolve a construção das mini-histórias, nesse momento, seja um ato de luta pelos direitos das crianças e que potencializa a construção de vínculos afetivos que, sólidos, esperamos perdurar após esse período de pandemia, quando pudermos nos encontrar presencialmente.

\section{Referências}

BARBOSA, M. C. S. (Cons.). Práticas Cotidianas na Educação Infantil -Bases para a reflexão sobre as orientações curriculares. Projeto de Cooperação Técnica MEC e UFRGS para construção de orientações curriculares para a Educação Infantil. Ministério da Educação. Secretaria de Educação Básica. Universidade Federal do Rio Grande do Sul. Brasília, 2009.

BRASIL, Ministério da Educação. Secretaria de Educação Básica. Diretrizes curriculares nacionais para a educação infantil. Secretaria de Educação Básica. - Brasília : MEC, SEB, 20I0. Disponível em: https://ndi.ufsc.br/files/2012/02/Diretrizes-Curriculares-para-a-E-I.pdf. Acesso em : II de Junho de 2020.

BRASIL. Resolução CNE/CEB I/20II. Conselho Nacional de Educação. Câmara da Educação Básica. Brasília: MEC, 20II. Diário Oficial da União, Brasília, II de março de 20II, Seção I, p. I0. Disponível em: https://nditeste.paginas.ufsc.br/files/20I2/I I/Resolu\%C3\%A7ao-n-I-I0-03-20 I I.pdf. Acesso em: 12 de junho de 2020.

BRASIL. Base Nacional Comum Curricular. Brasília: MEC, 2020. Disponível em: http://basenacionalcomum.mec.gov.br/abase/. Acesso em: I3 de maio de 2020.

DEPARTAMENTO DE SAÚDE COLETIVA, UFSM, 2020. Você sabe o que são coronavírus? Disponível em: https://www.ufsm.br/wp-content/uploads/2020/03/coronavirus.pdf . Acesso em: II de Junho de 2020.

FOCHI, P. S. A documentação pedagógica como estratégia para a construção do conhecimento praxiológico: o caso do Observatório da Cultura Infantil - OBECI. 2019. 347 páginas. Doutorado em Educação. Área: Didática, Teorias de Ensino e Práticas Escolares. Universidade de São Paulo. São Paulo, 2019.

MAYER, P.; VOSGERAU, D. S. R.; BORGES, C. Colaboração entre pares em programas de desenvolvimento profissional docente. Práxis Educativa, vol. 13, núm. 2, 2018. Disponível em: $<10.52$ |2/PraxEduc.v. |3i2.0004>.

PARREIRAS, N. Do ventre ao colo, do som à literatura. Editora RHJ. Belo Horizonte, 2012.

REYES, Y. A casa imaginária: leitura e literatura na primeira infância. $I^{\circ}$ ed. São Paulo: Global, 2010.

Olhar de professor, Ponta Grossa, v. 24, p. I-10, e-16064.034, 2021.

Disponível em <https://revistas2.uepg.br/index.php/olhardeprofessor> 
SANDRONI, L.; MACHADO, L.. A criança e o livro. São Paulo: Editora Ática, I99I.

SECRETARIA DE SAÚDE- RS, 2020. O que é COVID 19?. Disponível em: https://coronavirus.rs.gov.br/o-que-e. Acesso em: II de Junho de 2020.

UNIDAde de educaÇÃo INFANTIL IPÊ AMARelo /UFSM. Projeto Político Pedagógico. 2019.

Recebido em: 15 de junho de 2020.

Versão corrigida recebida em: 28 de outubro de 2021.

Aceito em: 28 de outubro de 2020.

Publicado online em: 23 de abril de 2021 .

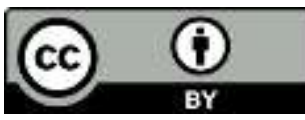

